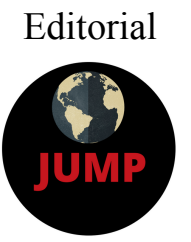

\author{
ISSN: 2574-3465 Print/ ISSN: 2574-3481 Online \\ Volume 2, Issue 1 (2018), pp. 1-3 \\ (C) Journal of Underrepresented and Minority Progress \\ http://minorityprogress.org/ \\ doi: $10.5281 /$ zenodo. 1322165
}

\title{
Health Equity and Progress for Underrepresented Minorities
}

\author{
Anita Hawkins \\ Morgan State University
}

\begin{abstract}
Diversity in the workplace has been recognized as a beneficial and profitable practice that fosters greater creativity and innovation generated from varied perspectives and experiences. (Richard \& Miller, 2013). Even in the public sector, the benefits of a diverse workforce are recognized. The U.S. Office of Personnel Management's (2016) strategic plan aims to attain a workforce representative of all segments of society with the objective of being more responsive in the provision of public service.
\end{abstract}

The strategy for achieving diversity in the workplace is by increasing the proportion of underrepresented minorities in the various professions and work settings. Such efforts fall into two primary categories: (1) those which focus on the identification, recruitment and retention strategies for qualified individuals and (2) those efforts which focus on education and workforce preparedness, i.e., increasing the pool of qualified URM from which to recruit. Both of these strategies depict the challenges to the representation of minorities with a very limited perspective. Without an examination of the full complexity of the issue, the narrowly focused solutions fall short of the desired outcome and may result in unintended consequences. Such is the case when workforce recruitment efforts are successful but the work environment is not equipped to manage diversity or when the unintended consequence of education and training is homogeneity of thought and minimization of variety in experiences and perspectives, thereby resulting in less creativity and innovation (Chrobot-Mason \& Aramovich, 2013). Finding the pathway to the desired outcome while avoiding unintended consequences warrants a systems thinking approach and a health framework. 
The health of underrepresented minorities and their communities is a driving factor challenging typical strategies. Health and well-being are intricately tied to what many consider to be non-health issues and policieseducation, housing, transportation, criminal justice, labor and environmental. People in poor health are less likely able to optimally take advantage of educational opportunities, which would decrease their likely hood to attain the education and training for the kind of employment that would improve their economic conditions. The smaller pool of minorities to fill positions in various segments of the workforce (i.e., medicine, other STEM fields, senior and executive level management positions in both the public and private sectors) leads to their underrepresentation. This is not meant to further stigmatize persons from populations identified as underrepresented minorities as uneducated and poor. The point is to make more obvious how policies and systemic practices perpetuate the underrepresentation of segments of the population in critical aspects of our society.

From a public health perspective, the aim is not diversity but health equity. Health equity is essential to the progress of underrepresented minorities. According to a report published by the Robert Wood Johnson Foundation health equity is defined as follows:

Health equity means that everyone has a fair and just
opportunity to be healthier. This requires removing obstacles to
health such as poverty, discrimination, and their consequences,
including powerlessness and lack of access to good jobs with
fair pay, quality education and housing, safe environments, and
health care. (Braveman, Arkin, Orleans, Proctor, \& Plough,
2017)

The current political climate in the U.S. poses a threat to efforts to promote health equity. Strategies intended to overcome inequities and promote diversity as well as any effort to creatively addressing the issues of disparities experienced and underrepresentation among minorities in various sectors are under attack. Anti-diversity appears to be growing or at least is more openly expressed, and subsequently efforts to promote diversity and to diminish disparities are being undermined and/or dismantled. Such an environment makes it all too easy to focus on the negatives - on the barriers and challenges to progressive thinking and action.

The Journal of Underrepresented Minority Progress (JUMP) provides an opportunity to recognize the negative but refocus on the positive 
and the potential via sharing stories of seized opportunities, and successfully met challenges by those who have experienced the phenomenon of being an underrepresented minority. It is through the sharing of such efforts that others may be inspired to conduct and disseminate studies and scholarly thought pieces. Dissemination of such works leads to an increase in the understanding of the systemic complexity of the phenomena creating disparities and challenging diversity while seeking to find less complicated solutions. Evidence is continually needed to advance and advocate health equity, and diversity and inclusion policies as best practices but also as an ethical imperative.

\section{REFERENCES}

Braveman, P., Arkin, E., Orleans, T., Proctor, D., \& Plough, A. (2017). What is health equity? Robert Wood Johnson Foundation.

Chrobot-Mason, D., \& Aramovich, N. P. (2013). The psychological benefits of creating an affirming climate for workplace diversity. Group \& Organization Management, 38(6), 659-689.

Office of Personnel Management. (2016). Government-wide diversity and inclusion strategic plan. Available at https://www.opm.gov/policy-data-oversight/ diversity-and-inclusion/reports/governmentwide-inclusive-diversitystrategic-plan-2016.pdf

Richard, O. C., \& Miller, C. D. (2013). Considering diversity as a source of competitive advantage in organizations. In Q. M. Roberson (Ed.), The Oxford handbook of diversity and work (pp. 239-250). New York: Oxford University Press.

Anita Hawkins, $\mathrm{PhD}$, is an associate professor in the School of Health \& Policy at Morgan State University. Her major research interests lie in the area health communication (e.g., health literacy, risk communication, cultural competency, etc.) and age-related differences in health communication needs, HIV risk behaviors and identification of best practices for prevention. 